\title{
Evidence for Pteridine Regulation of Lead-Mediated Inhibition of Uroporphyrinogen and Heme Formation in Rat Bone Marrow ${ }^{1}$
}

\author{
Ware R. Christenson, ${ }^{*}$ Lorelle L. Bestervelt, $\dagger$ and Walter N. Piper ${ }^{*, \dagger}, 2$ \\ *Department of Pharmacology, University of Nebraska Medical Center, Omaha, Nebraska 68105; and †Toxicology Program, School of Public Health, \\ and Department of Pharmacology, University of Michigan Medical School, Ann Arbor, Michigan 48109
}

Received August 23, 1991; accepted November 20, 1991

Evidence for Pteridine Regulation of Lead-Mediated Inhibition of Uroporphyrinogen and Heme Formation in Rat Bone Marrow. Christenson, W. R., Bestervelt, L. L., AND Piper, W. N. (1992). Toxicol. Appl. Pharmacol. 113, 138-143.

Uroporphyrin I (URO I) accumulation has been reported in the bone marrow of rats exposed to lead, suggesting a sensitivity of uroporphyrinogen III cosynthase (COSYN) to this heavy metal. Furthermore, it has been reported that a polyglutamated folate derivative may serve as a coenzyme for the catalytic action of hepatic uroporphyrinogen III cosynthase. These findings raised the question of whether depletion of polyglutamated folate could enhance the susceptibility of bone marrow COSYN to lcad and potentially interfere with the formation of heme. Nitrous oxide, an anesthetic agent capable of causing bone marrow tetrahydrofolate deficiency, depressed total bone marrow polyglutamated folate content by $42 \%$ with significant reductions in all three chain lengths (5-7) identified in the bone marrow during an exposure period of 7 days at $4 \mathrm{hr} /$ day. Lead acetate $(15 \mathrm{mg} /$ $\mathrm{kg}$ ) administered by ip injection at Days 0 and 2 during a 7-day exposure to nitrous oxide resulted in an $84 \%$ increase of bone marrow URO I content, which was markedly higher than the increases of 22 and $38 \%$ seen with sole administration of lead or nitrous oxide, respectively. The combination of agents also produced a $48 \%$ rise in COPRO I, a 39 and $43 \%$ decrease in COPRO III and protoporphyrin, respectively, and a $42 \%$ decline in the activity of microsomal 7-ethoxycoumarin $O$-deethylase, which is hemoprotein, cytochrome P-450 mediated. Heme oxygenase activity was not altered by nitrous oxide, lead, or their combination. These results suggest that bone marrow folate deficiency may render COSYN more sensitive to lead as characterized by increased uroporphyrin I and coproporphyrin I isomer content, decreased coproporphyrin III and protoporphyrin content, and depressed microsomal hemoprotein, cytochrome $\mathbf{P}$ 450-mediated drug-metabolizing capability. 1992 Academic Press, Inc.

There is widespread exposure to lead in our environment. Lead intoxication is known to cause anemia, and the biosynthesis of heme is inhibited by this heavy metal. However,

\footnotetext{
I This research was supported by Grant ES-02424 from the National Institutes of Health.

${ }^{2}$ To whom reprint requests should be addressed.
}

most information on lead-impaired heme formation has been performed with the erythrocyte which transports oxygen but does not have the enzymatic capability to synthesize heme.

The third step of heme biosynthesis is believed to be mediated by the concerted action of two enzymes in a two-step reaction. The first step is catalyzed by uroporphyrinogen (UROGEN) I synthase (URO-S) (EC 4.3.1.8), which converts four molecules of the pyrrole porphobilinogen into the unstable intermediate hydroxymethylbilane. The low activity of this enzymatic reaction in tissue indicates that this step may become potentially rate-limiting for the synthesis of heme. Hydroxymethylbilane, serving as the substrate for uroporphyrinogen III cosynthase (COSYN) (EC 4.2.1.75), is then converted into the biologically active heme precursor uroporphyrinogen III. Without COSYN, hydroxymethylbilane spontaneously cyclizes into uroporphyrinogen I, which is useless as a substrate for COSYN and thus cannot be utilized in the synthesis of heme. Uroporphyrinogen I is able to serve as a substrate for the next enzyme in the heme biosynthetic pathway, uroporphyrinogen decarboxylase, which forms coproporphyrinogen I. These uro- and coproporphyrinogens are rapidly oxidized to form uroporphyrin (URO) and coproporphyrin (COPRO). Therefore, COSYN can be considered a "specifier protein" that ensures the synthesis of uroporphyrinogen III from hydroxymethylbilane with the combined catalytic action of URO-S (Tait, 1978; Burton et al., 1979; Jordan et al., 1979).

The rare disease of congenital erythropoietic porphyria is believed to be due to an inherited enzymatic defect in uroporphyrinogen III cosynthase, causing excretion of excess URO I and COPRO I in the urine (Deybach et al., 1981). In addition, URO I accumulation has also been reported in the bone marrow of lead poisoned rats (Christenson et al., 1985) and rabbits (Schmid et al., 1952). These findings, together with a study by Kohashi et al. (1984) indicating that COSYN may require a reduced pteroylpolyglutamate coenzyme in order to facilitate UROGEN III biosynthesis, prompted us to investigate the effect of folate deficiency in regulating the toxic response of COSYN to lead in the bone marrow of the rat. 


\section{MATERIALS AND METHODS}

Chemicals. Folic acid, gelatin, reagent-grade Trizma Base, Coomassie brilliant blue G, bovine serum albumin (type V), NADPH, NADH (grade III), 7-ethoxycoumarin, umbelliferone (grade II), hemin (type III), isocitric acid, isocitric dehydrogenase, and heparin were obtained from Sigma Chemical Co. (St. Louis, MO). Porphobilinogen, protoporphyrin, uroporphyrin I octamethyl ester, uroporphyrin III octamethyl ester, coproporphyrin I tetramethyl ester, and coproporphyrin III tetramethyl ester were purchased from Porphyrin Products (Logan, UT). HPLC-grade acetonitrile and water were obtained from MCB Manufacturing Chemists, Inc. (Cincinnati, $\mathrm{OH}$ ), and HPLC-grade glacial acetic acid was purchased from J. T. Baker (Phillipsburg, NJ). Bio-Gel P2 (200-400 mesh) was obtained from Bio-Rad Laboratories (Richmond, CA). Pteroylpentaglutamate, pteroylhexaglutamate, and pteroylheptaglutamate standards were generous gifts from Dr. E. L. R. Stokstad at the University of California, Berkeley. All other laboratory reagents were of analytical grade and were purchased from Mallinckrodt Chemical Works (St. Louis, MO).

Animals. Adult, male Sprague-Dawley rats (Sasco, Omaha, NE; 180$200 \mathrm{~g}$ ) were housed in hanging cages in groups of three and were exposed to a 12-hr light/dark cycle (6:00 AM lights on; 6:00 PM lights off). Food (Purina Laboratory Rodent Chow, Ralston-Purina Co., St. Louis, MO) and water were provided ad libitum. Lead acetate, dissolved in $0.9 \% \mathrm{NaCl}$, was administered by ip injection at Days 0 and 2 followed by decapitation at 7 days. Controls received equivalent volumes of $0.9 \% \mathrm{NaCl}(4 \mathrm{ml} / \mathrm{kg})$. A deficiency of tetrahydrofolate in bone marrow was produced by exposure of rats to nitrous oxide, an inhibitor of methionine synthetase, which catalyzes the formation of tetrahydrofolate and methionine from methyltetrahydrofolate and homocysteine. For nitrous oxide experiments, rats were placed in a 30-liter specially constructed metabolic chamber through which flowed $\mathrm{N}_{2} \mathrm{O} / \mathrm{O}_{2}(1: 1)$ at $4 \mathrm{hr} /$ day $(9: 00 \mathrm{AM}-1: 00 \mathrm{PM})$ for 7 days. The total flow of gas was 8 liters $/ \mathrm{min}$. Controls were exposed to room air.

Tissue porphyrin analysis. Porphyrins were isolated from the bone marrow of the femur as described by Reddy et al. (1987). Uro- and coproporphyrin isomers were separated and quantitated by reverse-phase HPLC according to the methods of Rideout et al. (1983) and Wright et al. (1983), respectively. Protoporphyrin levels were also assessed by reverse-phase HPLC as described by Lim et al. (1984). All analyses were performed on a Waters Associates liquid chromatograph (Model 6000A solvent delivery system and Rheodyne 7125 injector) interfaced with a Schoeffel Model FS 970 fluorometer equipped with either a C18 bonded column (spherical $5 \mathrm{~mm}, 4.5 \mathrm{~mm}$ inner diameter $\times 25 \mathrm{~cm}$ ) from IBM Instruments, Inc. (Danbury, CT), for uro- and coproporphyrin determinations, or a $\mathrm{C} 1$ bonded column (spherical, $5 \mathrm{~mm}, 4.5 \mathrm{~mm}$ inner diameter $\times 15 \mathrm{~cm}$ ) from Shandon Instruments, Inc., (UK) for protoporphyrin analysis. A C18 bonded-guard column (spherical, $10 \mathrm{~mm} ; 4.6 \mathrm{~mm}$ inner diameter; $\times 3 \mathrm{~cm}$ ) from Brownlee Labs (Santa Clara, CA) was located between the pump and the analytical column.

Polyglutamated folate analysis. Bone marrow polyglutamated folate levels were determined utilizing the method of Shane (1982). All analyses were performed on a Perkin-Elmer Series 3 liquid chromatograph, utilizing a Perkin-Elmer Model 204A fluorescence spectrophotometer with excitation and emission wave lengths of 310 and $360 \mathrm{~nm}$, respectively, and a Whatman Partisil 10 SAX analytical column $(4.5 \mathrm{~mm} \times 25 \mathrm{~cm})$. A precolumn $(4.5$ $\mathrm{mm} \times 3 \mathrm{~cm}$ ) was placed before the injection port, and a guard column (4.6 $\mathrm{mm} \times 3 \mathrm{~cm})$ from Brownlee Labs containing a strong anionic exchanger was attached between the injection port and the analytical column.

Microsomal heme oxygenase assay. Bone marrow microsomal heme oxygenase activity was determined by the method of Ibrahim and Levere (1980). Product formation was found to be linear for $20 \mathrm{~min}$ with up to 1.0 $\mathrm{mg}$ of protein.

Assay of bone marrow microsomal drug metabolism. 7-Ethoxycoumarin $O$-deethylase activity was determined by the fluorometric assay method of Greenlee and Poland (1978), using the method of Dresner et al. (1981), in order to prepare bone marrow microsomes. Product formation was found to be linear for $15 \mathrm{~min}$ with up to $0.5 \mathrm{mg}$ of protein.

Protein. Protein concentrations were determined by the method of Bradford (1976) using bovine serum albumin as the standard.

Statistical analysis. Data were analyzed by a one-way analysis of variance using Tukey's $t$ test or by Student's $t$ test. A $p$ value less than 0.05 was required for significance of difference between means.

\section{RESULTS}

Effect of lead on uroporphyrin I and protoporphyrin content in rat bone marrow. Preliminary findings from this laboratory (Christenson et al., 1985) have indicated that uroporphyrin I accumulates in the bone marrow of lead poisoned rats. These findings would suggest a sensitivity of COSYN to lead. However, it has also been postulated that lead-mediated inhibition of ferrochelatase (EC 4.99.1.1), the last enzyme of the pathway, could account for uroporphyrin accumulation by causing a backup of porphyrin intermediates (Sassa et al., 1975). Therefore, to assess the specificity of the porphyrin response to lead in the bone marrow, a doseresponse study was conducted comparing changes in protoporphyrin, the substrate of ferrochelatase, to changes in uroporphyrin I levels (Fig. 1). At a dose of $30 \mathrm{mg} / \mathrm{kg}$ lead acetate, both URO I and protoporphyrin were increased. A $25 \%$ increase of URO I occurred at $15 \mathrm{mg} / \mathrm{kg}$, but proto-

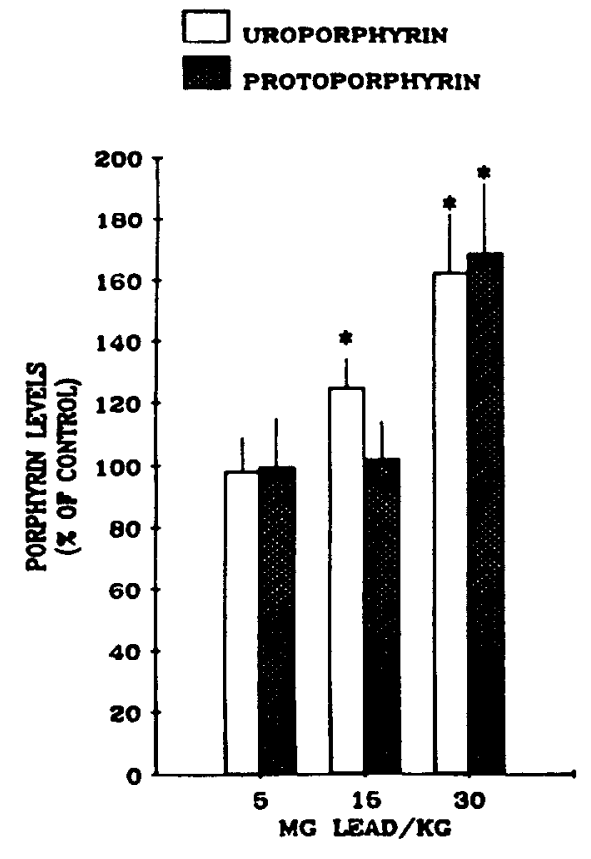

FIG. 1. The effect of lead on URO I and protoporphyrin content in rat bone marrow. Lead acetate was administered ip at Days 0 and 2 followed by euthanasia at Day 7. Marrow was assayed for URO I and protoporphyrin as described under Materials and Methods. Each bar represents the mean $\pm \mathrm{SE}$ for six rats. An asterisk denotes a significant difference $(p<0.05)$ between lead-treated and control rats. The mean control values for uroporphyrin I and protoporphyrin were 82.6 and $348.3 \mathrm{pmol} / \mathrm{g}$ tissue, respectively. 
porphyrin levels remained unchanged. Neither URO I nor protoporphyrin was increased at $5 \mathrm{mg} / \mathrm{kg}$. Therefore, the data suggest that COSYN may be subject to inhibition by lead, as characterized by URO I accumulation, and that the effect can occur at a dose that does not cause protoporphyrin accumulation, suggesting that URO I accumulates as a result of impaired COSYN.

Effect of lead, nitrous oxide, and their combination on uroporphyrin and polyglutamated folate content in rat bone marrow. The report of a polyglutamated folate moiety, functioning as a possible coenzyme to COSYN (Kohashi et al., 1984), and the observation that URO I accumulation, a condition indicative of COSYN inhibition, occurs in the bone marrow of lead poisoned experimental rats (Christenson et al., 1985) and rabbits (Schmid et al., 1952) raised the question as to whether the toxicity of lead toward COSYN might be modulated by the folate status of the tissue. To examine this question, rats were exposed to nitrous oxide at $4 \mathrm{hr} /$ day for 7 days. Nitrous oxide is an anesthetic agent known to reduce tissue polyglutamated tetrahydrofolate content (Perry et al., 1979; Scott et al., 1980). As shown in Table 1, bone marrow COSYN activity decreased over a 7day nitrous oxide exposure period. Table 1 also indicates that as the absolute activity of COSYN decreased, the percentage of uroporphyrinogen formed as isomer I increased. Groups of nitrous oxide-exposed rats were also given lead acetate at its apparent threshold for impairment of COSYN ( $15 \mathrm{mg} / \mathrm{kg}$ at Days 0 and 2 for 7 days). As shown in Fig. 2, a $72 \%$ increase in bone marrow uroporphyrin was observed in nitrous oxide-treated rats given lead acetate, which reflected an $84 \%$ increase in URO I content. This response was correlated to a $42 \%$ depression of total polyglutamated folate with significant reductions in all three chain lengths (Table 2) identified in the bone marrow. The simultaneous presence of lead had no effect on nitrous oxide-mediated reductions of polyglutamated folate. Lead acetate exposure alone failed to produce a significant increase of URO I in bone marrow or to alter polyglutamated folate content.

Effect of lead, nitrous oxide, and their combination on copro- and protoporphyrin content in rat bone marrow. Two

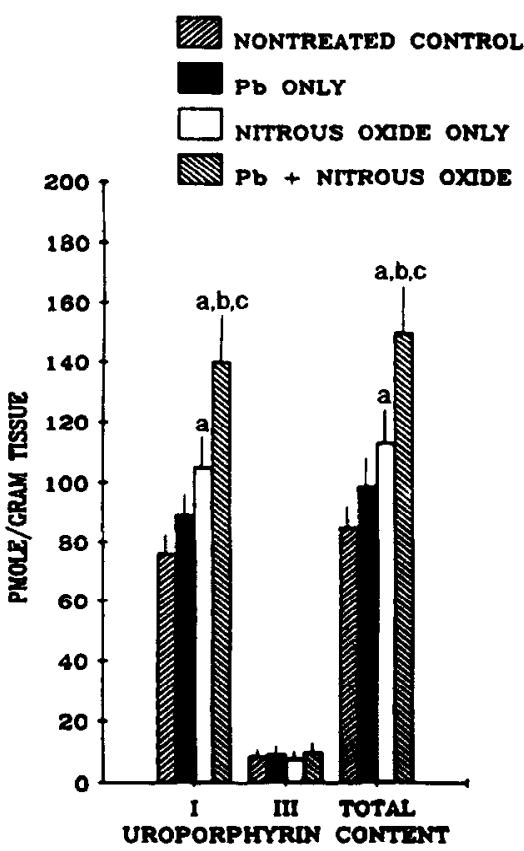

FIG. 2. The effect of lead, nitrous oxide, and their combination on uroporphyrin content in rat bone marrow. Lead acetate alone $(15 \mathrm{mg} / \mathrm{kg})$ was administered ip at Days 0 and 2 followed by euthanasia at Day 7 . Nitrous oxide/oxygen (1:1) was administered $4 \mathrm{hr} /$ day for 7 days. For combined administration, lead acctatc was injected at Days 0 and 2 during the 7-day exposure to nitrous oxide at $4 \mathrm{hr} /$ day. Following euthanasia, bone marrow was assayed for uroporphyrin as described under Materials and Methods. Each bar represents the mean \pm SE for three determinations. a, significant difference $(p<0.05)$ from control; $b$, significant difference $(p<0.05)$ from nitrous oxide; $c$, significant difference $(p<0.05)$ from lead.

isomeric forms (types I and III) of uroporphyrinogen, the initial tetrapyrrole of heme biosynthesis, are normally synthesized. However, only the more abundant type III form can be incorporated into heme. Consequently, a marked increase in uroporphyrinogen I rather than isomer III concentration could have a significant effect on heme biosynthesis if the change could be translated through the pathway from the site of action. To test this possibility, the levels of coproand protoporphyrin were also determined in the bone marrow following treatment of rats with lead, nitrous oxide, or

TABLE 1

Effect of Nitrous Oxide on Uroporphyrinogen III Cosynthase Activity in Rat Bone Marrowa

\begin{tabular}{|c|c|c|c|c|}
\hline 4 & $2.73 \pm 0.85$ & $21.7 \pm 2.5$ & $72.1 \pm 6.5$ & $27.9 \pm 4.3$ \\
\hline 7 & $2.52 \pm 0.77$ & $16.2 \pm 1.9^{b}$ & $59.6 \pm 6.0$ & $40.4 \pm 4.7$ \\
\hline
\end{tabular}

\footnotetext{
${ }^{a}$ Rats were exposed to $\mathrm{N}_{2} \mathrm{O} / \mathrm{O}_{2}(1: 1)$ at a rate of $4 \mathrm{hr} /$ day with controls receiving room air. Animals were then euthanized at 4 or 7 days and their bone marrow assayed as described under Materials and Methods. Values are the averages of three experiments and are expressed as the means \pm SEM.

${ }^{b} p<0.05$ when compared to respective control value.
} 
TABLE 2

Effect of Lead, Nitrous Oxide, and Their Combination on Polyglutamated Folate Content in Rat Bone Marrow ${ }^{a}$

\begin{tabular}{ccccc}
\hline Chain length & $\begin{array}{c}\text { Control } \\
(\mathrm{nmol} / \mathrm{g})\end{array}$ & $\begin{array}{c}\text { Lead } \\
(\mathrm{nmol} / \mathrm{g})\end{array}$ & $\begin{array}{c}\mathrm{N}_{2} \mathrm{O} \\
(\mathrm{nmol} / \mathrm{g})\end{array}$ & $\begin{array}{c}\mathrm{N}_{2} \mathrm{O} / \mathrm{lead} \\
(\mathrm{nmol} / \mathrm{g})\end{array}$ \\
\hline 2 & $\mathrm{ND}^{b}$ & $\mathrm{ND}$ & $\mathrm{ND}$ & $\mathrm{ND}$ \\
3 & $\mathrm{ND}$ & $\mathrm{ND}$ & $\mathrm{ND}$ & $\mathrm{ND}$ \\
4 & $\mathrm{ND}$ & $\mathrm{ND}$ & $\mathrm{ND}$ & $\mathrm{ND}$ \\
5 & $0.28 \pm 0.03$ & $0.32 \pm 0.02$ & $0.13 \pm 0.02^{c}$ & $0.14 \pm 0.03^{c}$ \\
6 & $0.21 \pm 0.02$ & $0.24 \pm 0.03$ & $0.10 \pm 0.04^{c}$ & $0.15 \pm 0.02^{c}$ \\
7 & $0.05 \pm 0.01$ & $0.06 \pm 0.01$ & $0.02 \pm 0.01^{c}$ & $0.03 \pm 0.01^{c}$ \\
Total & $0.54 \pm 0.02$ & $0.62 \pm 0.02$ & $0.25 \pm 0.03^{c}$ & $0.32 \pm 0.02^{c}$ \\
\hline
\end{tabular}

${ }^{a}$ Lead acetate $(15 \mathrm{mg} / \mathrm{kg})$ was administered ip at Days 0 and 2 followed by euthanasia at Day 7 . Nitrous oxide/oxygen (1:1) was administered over 7 days at $4 \mathrm{hr} /$ day (9:00 AM-1:00 PM). For combined administration, lead acetate was injected at Days 0 and 2 during a 7-day exposure to nitrous oxide at $4 \mathrm{hr} /$ day. Following euthanasia, bone marrow was assayed for polyglutamated folate as described under Materials and Methods. Values represent the means \pm SEM for three rats.

${ }^{b}$ None detected.

${ }^{c}$ Denotes a significant difference $(p<0.05)$ from control rats.

their combination. As depicted in Fig. 3, the combination of lead and nitrous oxide caused a $48 \%$ increase in COPRO I content that was accompanied by a $39 \%$ decrease in COPRO III. A $43 \%$ decrease in protoporphyrin, the last inter-

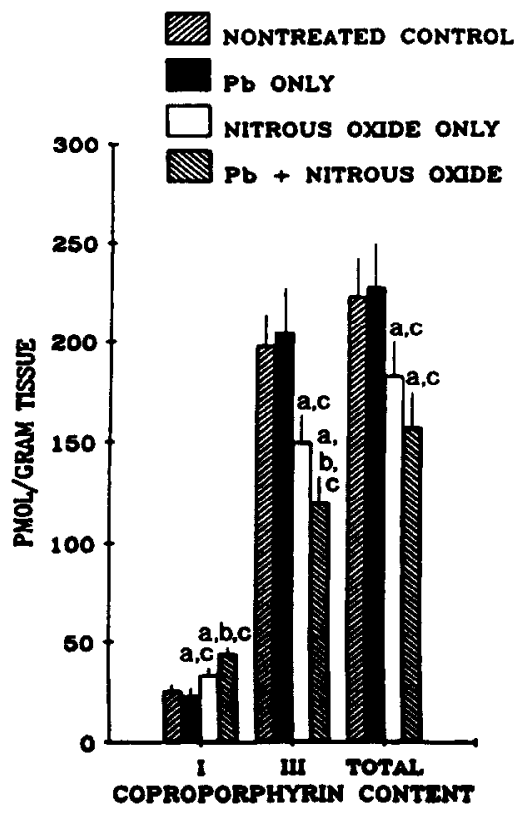

FIG. 3. The effect of lead, nitrous oxide, and their combination on coproporphyrin in rat bone marrow. Experimental conditions were identical to those described in the legend to Fig. 2. Each bar represents the mean \pm $\mathrm{SE}$ for three determinations. a, significant difference $(p<0.05)$ from control; $\mathrm{b}$, significant difference $(p<0.05)$ from nitrous oxide; $c$, significant difference $(p<0.05)$ from lead.

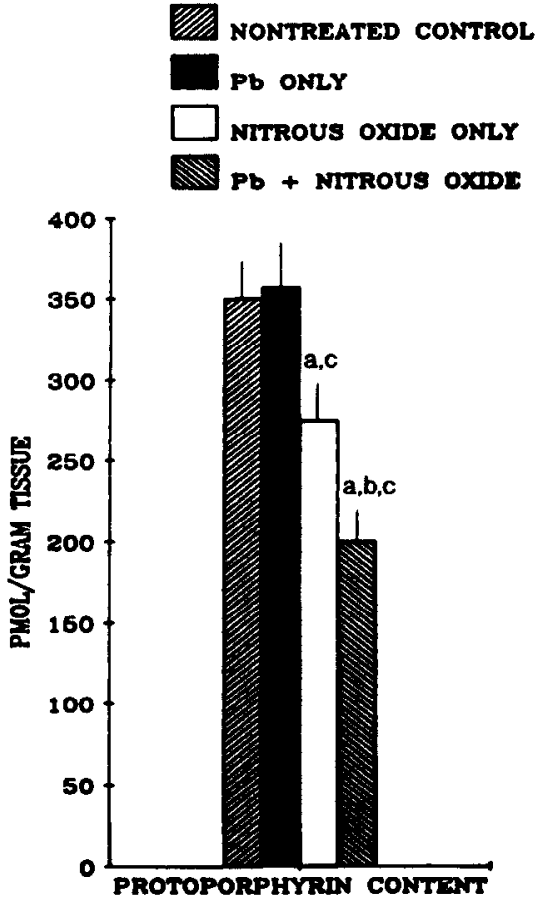

FIG. 4. The effect of lead, nitrous oxide, and their combination on protoporphyrin content in rat bone marrow. Experimental conditions were identical to those described in the legend to Fig. 2. Each bar represents the mean \pm SE for three determinations. a, significant difference $(p<0.05)$ from control; $\mathrm{b}$, significant difference $(p<0.05)$ from nitrous oxide; $c$, significant difference $(p<0.05)$ from lead.

mediate of heme biosynthesis, was observed (Fig. 4) in the bone marrow of rats exposed to lead and nitrous oxide. All changes were greater than those observed with administration of either lead or nitrous oxide alone, suggesting that the alterations in porphyrin content are initiated with uroporphyrinogen synthesis and were enhanced by exposure to nitrous oxide.

Effect of lead, nitrous oxide, and their combination on bone marrow microsomal drug metabolism. The observation that the combined action of lead and nitrous oxide results in a significant, potentiated accumulation of URO I and COPRO I, and a marked depression of protoporphyrin levels suggests that microsomal heme content may also be depressed. To test this possibility, hemoprotein, microsomal cytochrome P-450-mediated drug metabolism was determined by measuring the $O$-deethylation of 7-ethoxycoumarin to 7-hydroxycoumarin. As depicted in Fig. 5, 7-ethoxycoumarin $O$-deethylase activity was unaffected by treatment with lead but was decreased by $26 \%$ following nitrous oxide exposure. Coadministration of lead during nitrous oxide exposure resulted in a $42 \%$ decrease in enzymatic activity.

Effect of lead, nitrous oxide, and their combination on microsomal heme oxygenase activity. The observed reduction in 7-ethoxycoumarin $O$-deethylase activity produced by coadministration of lead and nitrous oxide could also be the 

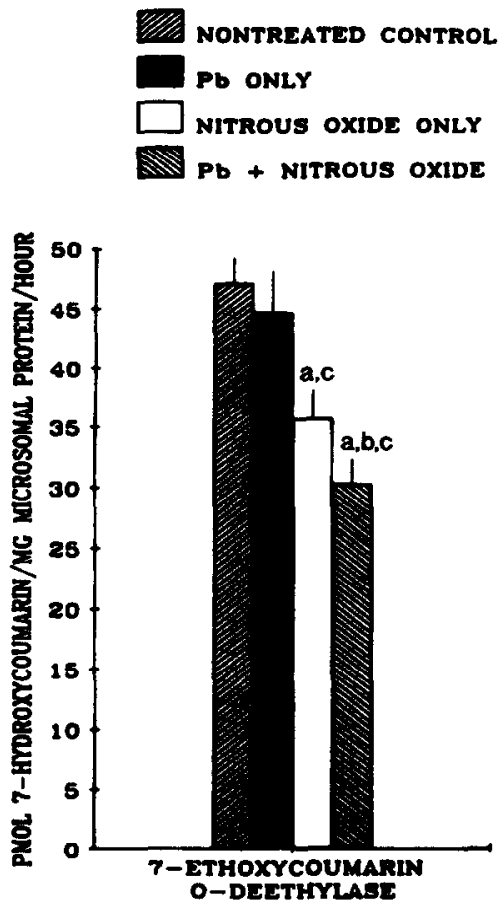

FIG. 5. The effect of lead, nitrous oxide, and their combination on bone marrow microsomal drug metabolism. Experimental conditions were identical to those described in the legend to Fig. 2. Each bar represents the mean \pm SE for three determinations. a, significant difference $(p<0.05)$ from control; $b$, significant difference $(p<0.05)$ from nitrous oxide; $c$, significant difference $(p<0.05)$ from lead.

result of an increase in the rate of heme catabolism. Microsomal heme oxygenase, the first and rate-limiting enzymatic step in the breakdown of heme, was assayed to test this possibility. Heme oxygenase activity was unaffected by the presence of lead, nitrous oxide, or their combination (Fig. 6). Therefore, it is unlikely that accelerated heme catabolism is responsible for the observed depression in microsomal drug metabolizing capability.

\section{DISCUSSION}

These studies indicate that the response of bone marrow COSYN to lead exposure can be modified as a function of the folate status of the tissue. Utilizing URO I tissue accumulation as an index to COSYN impairment, the dose-response experiment conducted indicates the susceptibility of COSYN to lead. Moreover, it suggests that at low doses of lead URO I buildup appears to begin prior to the protoporphyrin accumulation that is indicative of lead-mediated inhibition of ferrochelatase. This would suggest that COSYN may be more sensitive to lead toxicity than ferrochelatase, as evidenced by the earlier isomeric change in uroporphyrin I composition, which reflects the toxic response of COSYN to lead. However, at higher levels of lead exposure, uroporphyrin accumulation could result from a combination of intermediate backup from inhibition of ferrochelatase (Sassa et al., 1975) in addition to URO I accumulation from inhibition of COSYN.

An enhanced accumulation of URO I in bone marrow in rats treated with lead and exposed to nitrous oxide was observed during tetrahydrofolate deficiency. Furthermore, the effect was accompanied by increased accumulation of $\mathrm{CO}$ PRO I, decreased levels of COPRO III and protoporphyrin, and decreased activity of microsomal hemoprotein, cytochrome P-450 drug-metabolizing capability, suggesting a diminished microsomal heme content as a consequence of impaired uroporphyrinogen and heme formation.

It is unlikely that lead at the dose utilized acted to inhibit COSYN activity through modification of folate metabolism since the combination of agents failed to enhance the depression of bone marrow polyglutamated folate (Table 2). Thus, it is more likely that the potentiated effect on URO I observed is a consequence of the direct action of lead on a folate-dependent COSYN enzyme that is rendered more accessible to inhibition in the folate-deficient state. Such a possibility is consistent with a report by Piper and van Lier (1977) which indicated that pteroylpolyglutamates were capable of protecting against inhibition of rat hepatic URO-S by lead and that a one-carbon transfer may be involved in hydroxymethylbilane rearrangement to UROGEN III in the presence of COSYN (Battersby et al., 1978, 1979, and 1980), implying that diminished levels of polyglutamated folate could induce susceptibility to lead toxicity.

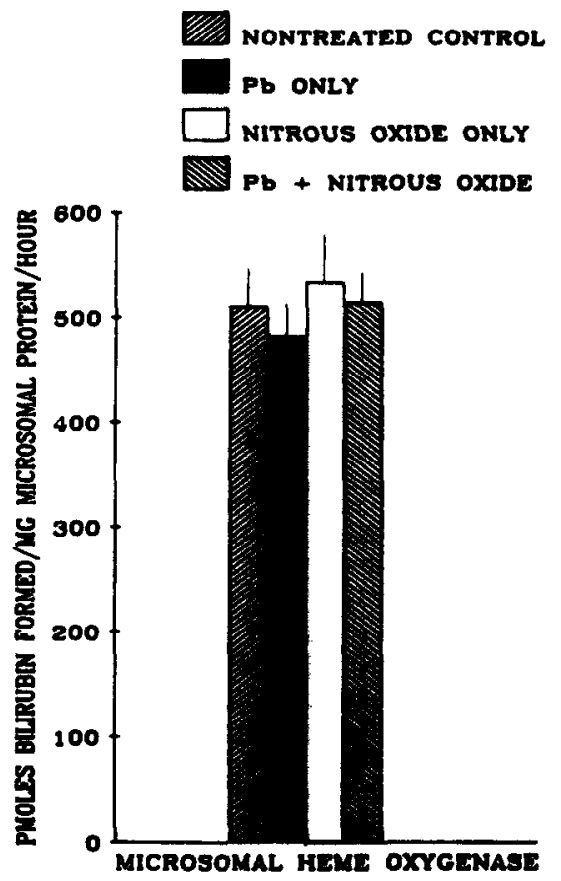

FIG. 6. The effect of lead, nitrous oxide, and their combination on bone marrow microsomal heme oxygenase activity. Experimental conditions were identical to those described in the legend to Fig. 2. Each bar represents the mean $\pm S E$ for three determinations. 
In conclusion, the data herein indicate that a folate derivative may play a central role in uroporphyrinogen III synthesis and the formation of heme by regulating the response of COSYN to environmental toxins such as lead. These findings are important with respect to the prevalence of folic acid deficiency in the United States together with the major problem that lead poisoning represents among nutritionally deficient members of society.

\section{REFERENCES}

Battersby, A. R., Fookes, C. J. R., Matcham, G. W. J., and McDonald E. (1980). Biosynthesis of the pigments of life: Formation of the macrocycle. Nature 285, 17-21.

Battersby, A. R., Fookes, C. J. R., Matcham, G. W. J., McDonald, E., and Gustafson-Potter, K. E. (1979). Biosynthesis of the natural porphyrins: Experiments on the ring-closure steps and with the hydroxy-analogue of porphobilinogen. J. Chem. Soc. Chem. Commun., 316-319.

Battersby, A. R., Fookes, C. J. R., McDonald, E., and Meegan, M. J. (1978). Biosynthesis of type III porphyrins: Proof of intact enzymic conversion of the heat-to-tail bilane into uro'gen III by intramolecular rearrangement. J. Chem. Soc. Chem. Commun., 185-186.

Bradford, M. (1976). A rapid and sensitive method for the quantitation of microgram quantities of protein utilizing the principle of protein dye binding. Anal. Biochem. 72, 248-254.

Burton, G., Fagerness, P. E., Hosozawa, S., Jordan, P. M., and Scott, A. I. (1979). ${ }^{13} \mathrm{C}$-NMR evidence for a new intermediate, pre-uroporphyrinogen, in the enzymic transformation of porphobilinogen into uroporphyrinogens I and III. J. Chem. Soc. Chem. Commun., 202-204.

Christenson, W. R., Reddy, R. V., and Piper, W. N. (1985). Uroporphyrin accumulation in the bone marrow of rats exposed to lead. Biochem. Pharmacol. 34, 4345-4347.

Deybach, J. C., Deverneuil, H., Phung, N., Nordmann, Y., Puissant, A., and Boffety, G. (1981). Congenital erythropoietic porphyria (Gunther's disease): Enzymatic studies on two cases of late onset. J. Lab. Clin. Med. 97, 551-558.

Dresner, J. H., Ibraham, N. G., and Levere, R. D. (1981). Presence and induction of drug metabolizing enzymes in rat bone marrow. Res. Commun. Chem. Pathol. Pharmacol. 32, 281-298.

Greenlee, W. F., and Poland, A. (1978). An improved assay of 7-ethoxycoumarin $O$-deethylase activity: Induction of hepatic enzyme activity in C57BL/6J and DBA/2J mice by phenobarbital, 3-methylcholanthrene and 2,3,7,8-tetrachlorodibenzo-p-dioxin. J. Pharmacol. Exp. Ther. 205, $596-605$.
Ibrahim, N. G., and Levere, N. G. (1980). Nucleotide requirements for the bone marrow heme oxygenase system. Life Sci. 26, 525-531.

Jordan, P. M., Burton, G., Nordlov, E., Schneider, M. M., Pryde, L., and Scott, A. I. (1979). Pre-uroporphyrinogen: A substrate for uroporphyrinogen III cosynthase. J.S.C. Chem. Comm., 204-205.

Kohashi, M., Clement, R. P., Tse, J., and Piper, W. N. (1984). Rat hepatic uroporphyrinogen III cosynthase: Purification and evidence for a bound folate coenzyme participating in the biosynthesis of uroporphyrinogen III. Biochem. J. 220, 755-765.

Lim, C. K., Rideout, J. M., and Peters, T. J. (1984). High performance liquid chromatography of dicarboxylic porphyrins and metalloporphyrins: Retention behavior and biomedical applications. J. Liq. Chromatogr. 317, 333-341.

Perry, J., Chanarin, I., Deacon, R., and Lumb, M. (1979). The substrate for folate polyglutamate biosynthesis in the vitamin $\mathbf{B}_{12}$-inactivated rat Biochem. Biophys. Res. Commun. 91, 678-684.

Piper, W. N., and Van Lier, R. B. L. (1977). Pteridine regulation of inhibition of hepatic uroporphyrinogen I synthetase activity by lead chloride. $\mathrm{Mol}$. Pharmacol. 13, 1126-1135.

Reddy, R. V., Christenson, W. R., and Piper, W. N. (1987). Extraction and isolation by high performance liquid chromatography of uroporphyrin and coproporphyrin isomers from biological tissues. J. Pharmacol. Methods 17, 51-57.

Rideout, J. M., Wright, D. J., and Lim, C. K. (1983). High performance liquid chromatography of uroporphyrin isomers. J. Liq. Chromatogr. 612 , 383-394.

Sassa, S., Granick, S., and Kappas, A. (1975). Effect of lead and genetic factors on heme biosynthesis in the human cell. Ann. N.Y. Acad. Sci. 244, 419-439.

Schmid, R., Hanson, B., and Schwartz, S. (1952). Experimental porphyria I. Isolation of uroporphyrin I from bone marrow If lead poisoned rabbits. Proc. Soc. Exp. Biol. Med. 79, 459-462.

Scott, A. I., Burton, G., Jordan, P. M., Matsumoto, H., Fagerness, P. E., and Pryde, L. M. (1980). NMR spectroscopy as a probe for the study of enzyme-catalysed reactions. Further observations of preuroporphyrinogen, a substrate for uroporphyrinogen III cosynthetase. J. Chem. Soc. Chem. Commun. 384.

Shane, B. (1982). High performance liquid chromatography of folates: Identification of poly- $\gamma$-glutamate chain lengths of labeled and unlabeled folates. Am. J. Clin. Nutr. 35, 599-608.

Tait, G. H. (1978). In Heme and Hemoproteins. (F. De Matteis and W. N. Aldridge, Eds.), pp. 1-48. Springer-Verlag, New York.

Wright, D. J., Rideout, J. M., and Lim, C. K. (1983). High performance liquid chromatography of coproporphyrin isomers. Biochem. J. 209, 553555. 